\title{
Panorama geral dos estudos sobre a aquisição do Português L2 em Moçambique
}

\section{Overview of Studies on the Acquisition of Portuguese as L2 in Mozambique}

Carlito A. Companhia*

ccompanhia@yahoo.com.br

Universidade Eduardo Mondlane

\begin{abstract}
RESUMO: O presente artigo tem como objectivo proporcionar uma visão geral dos estudos já efectuados sobre a aquisição do Português L2 em Moçambique. De um modo específico, procura-se apresentar os resultados da pesquisa já realizada em torno dos estágios intermediários das gramáticas da interlíngua dos aprendentes (DINIZ, 1986; GONÇALVES; NILSON; NGUNGA, 1986; ALMEIDA, 2001; CANDE, 2001; COMPANHIA, 2001; DIAS, 2009a e b; GONÇALVES, 2010; DZECO, 2011), do papel da transferência linguística (GONÇALVES; NILSON; NGUNGA, 1986; GONÇALVES, 2010), do padrão de desenvolvimento linguístico (DIAS, 2009b; GONÇALVES, 2010) e do papel do contexto social na aquisição do Português L2 (COMPANHIA, 2016). Finalmente, apresentam-se as linhas de investigação que se podem desenvolver, tendo em consideração as lacunas existentes neste campo de pesquisa.
\end{abstract}

PALAVRAS-CHAVE: Estudos sobre aquisição. Português L2. Moçambique.

ABSTRACT: This article aims to provide an overview of the studies already carried out on the acquisition of the Portuguese L2 in Mozambique. In a specific way, it seeks to present the results of research conducted on the intermediate stages of learners' interlanguage grammar (DINIZ, 1986; GONÇALVES; NILSON; NGUNGA, 1986; ALMEIDA, 2001; CANDE, 2001; COMPANHIA, 2001; DIAS, 2009a e b; GONÇALVES, 2010; DZECO, 2011), the role of linguistic transfer (GONÇALVES; NILSON; NGUNGA, 1986; GONÇALVES, 2010), the pattern of language development (DIAS, 2009b; GONÇALVES, 2010) and the role of social context in the acquisition of Portuguese as L2 (COMPANHIA, 2016). Finally, the lines of research that can be developed in view of the gaps in this field of research are presented.

KEYWORDS: Acquisition studies. Portuguese as L2. Mozambique.

\footnotetext{
* Doutor em Linguística pela Universidade Eduardo Mondlane (UEM), Maputo-Moçambique.
} 


\section{Introdução}

Em Moçambique, o Português, língua escolhida como oficial a partir da independência (1975), é para a maior parte dos falantes uma língua segunda (L2), num contexto sociolinguístico caracterizado pelo contacto entre esta língua e outras do grupo bantu. Este facto tem uma influência significativa na formação de uma variedade de língua que apresenta alterações gramaticais relativamente ao Português Europeu (PE) ao nível do discurso oral e escrito - o Português de Moçambique (PM). Tais alterações manifestam-se fundamentalmente a nível de determinadas áreas, nomeadamente fonética, sintaxe e morfo-sintaxe (cf. Gonçalves, 2010).

Do ponto de vista da aquisição da língua, a variante a que os aprendentes estão expostos é predominantemente a variante moçambicana do Português. Isto significa que os aprendentes têm acesso às variedades da língua-alvo "estruturadas de forma complexa" (STROUD, 1997, p. 36), facto que tem implicações ao nível dos processos e produtos de aquisição por parte dos aprendentes na medida em que "a variedade que os aprendentes são supostos adquirir, isto é, a variedade padrão seguindo a norma europeia quase nunca se encontra na comunicação real fora da escola" (HYLTENSTAM; STROUD, 1998, p. 237).

Desde os anos 1980, os investigadores têm-se dedicado ao estudo de diferentes aspectos relacionados com a aquisição do Português L2 em Moçambique, tendo produzido informações sobre as áreas de dificuldade na aquisição e uso desta língua. De um modo geral, os temas abordados nestes estudos podem ser agrupados em quatro áreas, nomeadamente estágios intermediários das gramáticas de interlíngua, papel da transferência linguística, padrão de desenvolvimento linguístico e papel do contexto social na aquisição do Português L2. Em todas estas áreas, à excepção do uso da preposição com, da concordância (nominal e verbal) e da flexão de verbos irregulares, os principais tópicos gramaticais abrangidos pelos estudos dizem respeito às estruturas e conectores de subordinação $e$ ao comportamento sintáctico de argumentos verbais com o papel de beneficiário, locativo e direccional. 
Em termos metodológicos, estes estudos envolvem aprendentes do Português $L 2^{1}$ de diferentes classes do ensino primário ( $3^{\mathrm{a}}, 4^{\mathrm{a}}, 5^{\mathrm{a}}$ e $7^{\mathrm{a}}$ classes), com diferentes línguas maternas (L1s) (nyanja, macua, ronga e changana) ${ }^{2}$ e adoptam, em geral, uma linha de pesquisa quantitativa recorrendo a testes de elicitação (DIAS, 2009a; COMPANHIA, 2016) e qualitativa, tomando como base empírica dados escritos constituídos por redacções (DINIZ, 1986; GONÇALVES; NILSON; NGUNGA, 1986; DIAS, 2009a; 2009b; GONÇALVES; MACIEL, 1998; GONÇALVES, 2010; DZECO, 2011) e dados orais obtidos através de entrevistas (ALMEIDA, 2001; CANDE, 2001; COMPANHIA, 2001; GONÇALVES, 2010).

$O$ presente artigo tem como objectivo proporcionar um panorama geral dos estudos já efectuados sobre a aquisição do Português L2 em Moçambique. A base de dados usada para os efeitos do presente trabalho inclui livros e artigos publicados em obras de especialidade bem como teses (não publicadas) de licenciatura, mestrado e doutoramento. Por forma a extrair algumas conclusões sobre os estudos, optou-se por organizá-los tendo por base a área a que o estudo se refere. Para cada área, faz-se uma apresentação dos principais tópicos gramaticais estudados bem como uma caracterização das principais dificuldades dos aprendentes.

A principal motivação para a realização deste estudo decorre da necessidade de contribuir para a divulgação da investigação já realizada na área da aquisição do Português L2, tendo em vista a identificação das áreas onde se desenvolve(ra)m mais estudos, incluindo as lacunas existentes nesta área. Com esta informação, é possível estabelecer linhas para pesquisas futuras, tendo em vista o alargamento da base teórica no campo da Aquisição de Língua Segunda (AL2) em geral.

$O$ artigo encontra-se estruturado da seguinte forma: estudos sobre os estágios intermediários da gramática (secção 1); estudos sobre o papel da transferência linguística na aquisição do Português L2 (secção 2); estudos sobre o padrão de desenvolvimento linguístico na aquisição do Português L2 (secção 3); estudos sobre o papel do contexto social na aquisição do Português (secção 4) e, finalmente, conclusões e perspectivas de investigação.

\footnotetext{
${ }^{1}$ Neste trabalho, considera-se o PE como sendo a língua-alvo.

2 Tanto quanto sei, à excepção do estudo de Pereira (1991), os estudos sobre a gramática de aprendentes do Português como L1 estão quase ausentes.
} 


\section{Estudos sobre os estágios intermediários das gramáticas de interlíngua}

Os estudos sobre os estágios intermediários das gramáticas de interlíngua dos aprendentes do Português L2 abarcam diferentes tópicos: estruturas e conectores de subordinação (DINIZ, 1986; GONÇALVES; NILSON; NGUNGA, 1986; GONÇALVES; MACIEL, 1998; GONÇALVES, 2010); comportamento sintáctico de argumentos verbais com 0 papel de beneficiário, locativo e direccional (GONÇALVES, 2010); uso da preposição com (DIAS, 2009a); concordância nominal (COMPANHIA, 2001; DZECO, 2011) e verbal em diferentes contextos sintácticos (ALMEIDA, 2001; DIAS, 2009b); e flexão de verbos irregulares (GONÇALVES; NILSON; NGUNGA, 1986; ALMEIDA, 2001; COMPANHIA, 2016).

Os resultados das pesquisas realizadas na área das estruturas de subordinação revelam que as dificuldades dos aprendentes relacionam-se, sobretudo, com os mecanismos sintáctico-semânticos envolvidos no encaixe de orações subordinadas completivas, relativas e adverbiais (temporais, finais, condicionais e infinitivas) (GONÇALVES; NILSON; NGUNGA, 1986; DINIZ, 1986; GONÇALVES; MACIEL, 1998; GONÇALVES, 2010). De entre os fenómenos gramaticais mais salientes, destaca-se a tendência para o uso sobregeneralizado do complementador universal que (cf. exemplo (1a)), a justaposição de frases subordinadas entre as quais existe uma dependência sintáctica (semântica) que exigiria o emprego de conectores que assinalassem essa relação de subordinação (cf. exemplo (1b)), o uso da preposição com o pronome relativo (cf. exemplo (1c)) e frases completivas (cf. exemplo (1d)), a dupla marcação de funções sintácticosemânticas (cf. exemplo (1e)), a colocação de frases relativas (cf. exemplo (1f)), e finalmente a flexão verbal (cf. exemplo (1g)). Exemplos:

(1) a. São animais bravios que a pele dele serve para confecção" (= ... cuja pele...)

b. Custuma levar chima ou décimos de peixe colocar no anzol $(=\ldots$ para colocar...)

c. A preparação desta dança só preparam no tempo que não há chuva $(=\ldots$ em que...)

d. As pessoas dizem de que a dança de nganda é muito importante ( $=\ldots$ que...)

e. Existem muitos ladrões que esses ladrões roubam muito $(=\ldots$ que roubam muito) 
f. Que podes levar a pessoa para o hospital também a ambulância é o transporte $(=\ldots$ a ambulância é $o$ transporte que pode levar a pessoa para 0 hospital)

g. Se a pessoa se dar incontro com ele pode ser matado $(=\ldots$ der...)

No domínio do comportamento sintáctico-semântico dos argumentos verbais, as dificuldades dos aprendentes manifestam-se ao nível do estabelecimento das propriedades de selecção categorial de verbos de diferentes classes sintácticosemânticas (CANDE, 2001; GONÇALVES, 2010). Assim, no que respeita ao comportamento sintáctico do argumento beneficiário, a gramática dos aprendentes caracteriza-se pela tendência para a realização como Sintagma Nominal (SN) de argumentos verbais, que, no $\mathrm{PE}$, têm a função de complemento indirecto e são regidos pela preposição a (cf. exemplo (2a)), incluindo casos de regência de objecto directo por essa mesma preposição (cf. (2b)). Quanto aos argumentos locativos e direccionais, o traço mais saliente relaciona-se com a alteração das propriedades de selecção categorial dos verbos de movimento, destacando-se a tendência para a escolha de uma preposição diferente daquela que é requerida pela norma do PE (cf. exemplo (2c)). Exemplos:

(2) a. Tiraram um pouco de arroz deram os cães ( $=\ldots$ aos...)

b. Deixaram ao coelho ( $=\ldots$ o coelho)

c. Quando eu volto da escola vou em casa $(=\ldots$ para...)

No que se refere ao uso da preposição com, descrita por Dias (2009a), as dificuldades dos aprendentes prendem-se com a utilização desta preposição em contextos em que deveria ser utilizada uma preposição diferente (cf. exemplo (3a)), com a substituição da conjunção e pela preposição com quando os elementos coordenados estão ligados por adição (cf. exemplo (3b)), com o seu uso como introdutor do agente da passiva (cf. exemplo (3c)) e, finalmente, com a introdução do agente focalizado (cf. exemplo (3d)). Exemplos:

(3) a. Eu despedi-me com a minha mãe (=... da minha mãe)

b. Eu com ele vamos ao mecado (= Eu e ele...)

c. Ele foi apanhado com a polícia (=... pela polícia) 
d. Bateram-Ihe com amigo dele (= O amigo dele bateu nele)

$\mathrm{Na}$ área da concordância nominal, as dificuldades dos aprendentes do Português L2 reflectem-se no estabelecimento das regras de concordância nominal no interior do SN (COMPANHIA, 2001; DZECO, 2011). Neste domínio, o principal traço gramatical que caracteriza a gramática de interlíngua dos aprendentes relaciona-se com a ausência de concordância entre os determinantes (artigos, numerais e possessivos) e o nome (cf. exemplos (4a-c)) e entre o nome e os adjectivos (cf. exemplo (4d)). Exemplos:

(4) a. Às vezes os professor chega aquela hora atrasada (=... professores...)

b. Era dois menino (=... meninos)

c. Estava a rasgar tuas coisa $(=\ldots$ coisas $)$

d. Serve também para irrigar e para os trabalhos industrial $(=\ldots$ trabalhos industriais)

Relativamente à área da concordância verbal, as principais dificuldades dos aprendentes de Português L2 relacionam-se com a ausência de concordância entre o sujeito e o verbo em diferentes contextos sintácticos (ALMEIDA, 2001; DIAS, 2009b). O aspecto mais saliente neste domínio tem a ver com a tendência para o uso do verbo na $3^{a}$ pessoa do singular em contextos em que o sujeito se encontra em diferentes pessoas gramaticais (cf. exemplos (5)) e com o enfraquecimento da concordância verbal em construções com sujeito pronominal pleno ( $1^{\text {a }}$ pessoa do singular) quer em frases simples (cf. exemplo (6a)), quer em frases complexas formadas por coordenação ou subordinação (cf. exemplos (6b e c, respectivamente)). Exemplos:

(5) a. Eu não entra na estrada (=... entro...)

b. Nós perdeu muita coisa $(=\ldots$ perdemos...)

c. Os polícias disse "não! Fica" (= ... disseram...)

(6) a. Eu foi levar matope (=... fui...)

b. Eu levou e fez um batuque (=... levei....fiz....)

c. Eu foi até ao rio levar barro para fazer uma boneco (=... fui....) 
No que se refere à flexão de verbos irregulares, Companhia (2016) verifica que a flexão de verbos irregulares no presente e imperfeito do conjuntivo constitui uma área complexa para os aprendentes do Português L2. Neste estudo, o autor constata que as dificuldades dos aprendentes do Português L2 prendem-se com a sobregeneralização da regra de flexão dos verbos irregulares (cf. exemplo (7a)) e com a escolha de diferentes tempos do indicativo em contextos onde deveriam ocorrer outros tempos (cf. exemplo (7b)). ${ }^{3}$ Exemplos:

(7) a. O tio quer que o Pedro não perda a corrida e fique em primeiro lugar (PE=...perca...).

b. O tio quer que o Pedro traz bons resultados da escola e passe de classe. $(\mathrm{PE}=\ldots$.traga ...)

\section{Estudos sobre o papel da transferência linguística na aquisição do Português L2}

Os resultados dos estudos sobre o papel da transferência linguística na aquisição do Português L2 evidenciam aspectos relacionados com a actuação da gramática das línguas bantu L1 dos aprendentes no processamento das evidências geradas pela gramática da língua-alvo. As áreas gramaticais cobertas por esses estudos abrangem tópicos no domínio do discurso citado e relatado (GONÇALVES; NILSON; NGUNGA, 1986), da regência de argumentos verbais e do uso de conectores de subordinação (GONÇALVES, 2010).

O estudo de Gonçalves, Nilson e Ngunga (1986) aborda o papel da transferência linguística da L1 dos aprendentes do Português L2 na produção "erros" do discurso citado e discurso relatado com a estrutura $\mathrm{V}_{\text {declarativo }}+q u e$ (própria do

3 Outros estudos também exploram aspectos relacionados com a flexão de verbos irregulares. Gonçalves, Nilson e Ngunga (1986) diagnosticam casos relacionados com a flexão de verbos irregulares no futuro e imperfeito do conjuntivo em frases condicionais e temporais. Exemplos:

(1) a. Se a pessoa se dar incontro com ele pode ser matado (= ... der ...)

b. Se fosse preciso compra-se uma farda (=... for...)

Embora orientado para o estudo das regras de concordância verbal, o estudo desenvolvido por Almeida (2001) também merece alguma referência no âmbito das pesquisas realizadas sobre a flexão verbal na interlíngua de aprendentes do português L2, dado que, neste estudo, a autora identifica casos que envolvem dificuldades associadas à flexão verbal do verbo irregular fazer. Exemplos:

(2) a. Eu não fazei (=... fiz...)

b. Meu pai fizeu uma cazinha para ele sentar $(=\ldots$ fez...) 
discurso citado em Português) seguida de citação textual (cf. exemplo (8)). Tendo em vista a explicação deste tipo de erros, os autores argumentam a favor da hipótese, segundo a qual as dificuldades dos aprendentes resultam da transferência linguística e, mais particularmente, do facto de nas línguas bantu existir uma estrutura do discurso citado em que este é introduzido por um complementador equiparável a que. Exemplo:

(8) Responderam que estamos a fugir de fogo (= Responderam: estamos a fugir do fogo/Responderam que estavam a fugir do fogo).

A pesquisa desenvolvida por Gonçalves (2010) destaca o papel das línguas bantu L1 dos aprendentes na emergência de novas propriedades gramaticais do PM ao nível dos argumentos beneficiário, locativo e direccional e dos conectores de subordinação. Neste estudo, a autora verifica, por um lado, que os fenómenos gramaticais do PM relacionados com a alteração do comportamento dos argumentos verbais [+ humano] que no PE têm a função de objecto indirecto (OI) e objecto directo (OD) (cf. exemplos (9a-b)) e de argumentos locativos e direccionais seleccionados por verbos de movimento (cf. exemplos (9c-d)) resultam da retenção na gramática do PM de valores de parâmetro das línguas bantu com particular destaque, respectivamente, ao sistema de marcação casual, às propriedades sintácticas dos constituintes locativos e ao padrão de lexicalização dos verbos de movimento destas línguas. Por outro lado, a autora verifica que as alterações no formato dos conectores de orações subordinadas completivas e adverbiais (cf. exemplos (9e-f)) decorre da ausência do traço [- SCOMP] seleccionado por preposições e advérbios na gramática das línguas bantu e da existência de complementadores complexos na gramática destas línguas. Exemplos:

(9) a. Tiraram um pouco de arroz deram os cães (=... aos...)

b. Deixaram ao coelho (=... o coelho)

C. Na minha casa é perto da estrada (= A minha casa...)

d. Buscar caniço para vir aqui na escola (=... à escola)

e. Viram de que afinal o coelho é esperto (= Viram que...)

f. Embora que os responseis também sofre (= Embora os responsáveis...) 


\section{Estudos sobre o padrão de desenvolvimento linguístico na aquisição do} Português L2

Os estudos que tratam do padrão de desenvolvimento linguístico dos aprendentes do Português L2 em Moçambique abordam tópicos relacionados com a fixação do parâmetro pro-drop ${ }^{4}$ (DIAS, 2009b), com o comportamento sintáctico de argumentos verbais com o papel de beneficiário, locativo e direccional, e com o uso de conectores de subordinação (GONÇALVES, 2010).

Os resultados do estudo levado a cabo por Dias (2009b) mostram que, na interlíngua dos aprendentes do Português $L 2$, existem três estágios de aquisição do parâmetro pro-drop: no primeiro estágio, verifica-se uma tendência para uma fixação negativa deste parâmetro, caracterizada pelo uso do sujeito pleno e pelo enfraquecimento da concordância verbal (cf. exemplo (10a)); no segundo estágio, regista-se uma tendência para uma aquisição progressiva do parâmetro pro-drop com o uso de frases com sujeito pleno e também de frases com sujeito nulo (cf. exemplos (10b-c)); no terceiro estágio, a interlíngua dos aprendentes caracteriza-se pela fixação positiva do parâmetro pro-drop com o uso de frases com sujeito nulo (cf. exemplo (10c)). Exemplos:

(10) a. Eu inventou uma palhota (=... inventei...)

b. Eu leva e foi vender aquela bola (=... levei...fui...)

c. Arranjei uns dois paus.

Por seu lado, a pesquisa realizada por Gonçalves (2010) destaca a emergência, logo nos primeiros estágios de desenvolvimento linguístico, de hipóteses divergentes relativamente à gramática do Português L2, que acabam por ser retidas no estágio final de aquisição do PM, revelando, assim, que o processo de reestruturação gramatical não altera substancialmente as hipóteses iniciais. Assim, no que diz respeito ao argumento beneficiário, este estudo mostra que, nos estágios iniciais de aquisição desta área gramatical, emergem duas hipóteses principais. A

\footnotetext{
${ }^{4} \mathrm{O}$ parâmetro pro-drop, também designado parâmetro de sujeito nulo, refere-se à variação entre as línguas no que diz respeito à realização lexical (ou não) do sujeito. Existem, com efeito, línguas que fixam positivamente este parâmetro [+ pro drop] como é o caso do PE, Espanhol e Italiano. Há outras, como o Inglês, que fixam negativamente este parâmetro [- pro drop].
} 
primeira considera que os argumentos OI/PE e OD beneficiário [+ humano]/PE ocorrem tipicamente realizados como $\mathrm{SN}$, e pronominalizam através da forma dativa do PE, Ihe (cf. exemplos (11)). A segunda hipótese dá conta de que tanto os argumentos OI/PE como os argumentos OD beneficiário [+ humano]/PE são regidos por preposição a (cf. exemplos (12)). Exemplos:

(11) a. Vou contar meus irmãos estórias. (=... aos meus irmãos)

b. Quando Ihe amarrarem costumam Ihe atirar no rio $(=\ldots$ o amarrarem....atirálo...).

(12) a. Entregou sapatos ao pombo

b. Leva faca faquear ao amigo (=... esfaquear o amigo...)

No que se refere aos argumentos verbais locativos e direccionais, a autora considera que, nesta área gramatical, ao longo do desenvolvimento linguístico dos aprendentes emergem quatro hipóteses. Numa primeira fase, os argumentos locativos com funções sintácticas nucleares de sujeito (cf. exemplo (13a)) e objecto directo (cf. exemplo (13b)) podem ser realizados sintacticamente como SP, regidos pela preposição em, enquanto os argumentos locativos com a função sintáctica de oblíquo podem ser realizados como SN (cf. exemplo (13c)). Para além destas hipóteses, a autora constata que os verbos de movimento incorporam informação sobre "percurso/direcção», podendo os seus argumentos ser sintacticamente realizados como SP regidos pela preposição em (cf. exemplo (13d)). Numa segunda fase, os argumentos locativos sintacticamente realizados como SP regidos pela preposição em podem ser regidos pela preposição para (cf. exemplo (13e)). Exemplos:

(13) a. Na minha casa não é longe (= A minha casa...)

b. Vou visitar em casa dos meus tios (= ... a casa...)

c. Eu não paro nenhum sítio (= em nenhum sítio)

d. Tomei banho, vim na escola (=... para a escola)

e. Foi para em casa daquela menina. (=... para casa...)

Finalmente, no que se refere aos conectores de subordinação, o estudo revela que, no processo de desenvolvimento linguístico desta área gramatical, 
emergem duas hipóteses sobre os itens lexicais que podem ocupar a posição de núcleo de sintagma do complementador em orações subordinadas completivas e adverbiais. A primeira dá conta que, numa primeira fase, esta posição é tipicamente preenchida pelo complementador universal que (cf. exemplo (14a)), enquanto a segunda postula que a posição de núcleo de SCOMP pode ser preenchida por preposições (cf. exemplo (14b)). Exemplos:

(14) a. Perguntou que lhes conhecia o nome dela (= ...perguntou se...)

b. Descansaram até chegou um leão (= ....até que chegou/até chegar....)

\section{Estudos sobre o papel do contexto social na aquisição do Português L2}

Tanto quanto é do meu conhecimento, o único estudo que trata do papel do contexto social na aquisição do Português L2 é o estudo de Companhia (2016). Neste estudo, o autor analisa a relação entre a aquisição de áreas periféricas e complexas da gramática com particular referência à flexão de verbos irregulares no presente e imperfeito do conjuntivo e o acesso à língua portuguesa em contexto natural em diferentes zonas de residência (urbana, suburbana e rural). Esta investigação é também complementada por uma análise das atitudes dos informantes destas zonas em relação ao uso do Português e das línguas bantu, bem como das orientações motivacionais em relação à aprendizagem destas línguas.

Os resultados deste estudo revelam que existe uma relação entre a competência linguística no domínio da flexão de verbos irregulares no presente e imperfeito do conjuntivo e o grau de exposição à língua portuguesa por parte dos aprendentes das diferentes zonas de residência seleccionadas. Para além disso, os resultados também mostram que as preferências dos aprendentes em relação às línguas de comunicação não diferem muito da zona urbana para a suburbana. Nestas zonas, a maior parte dos aprendentes prefere comunicar-se em Português, sendo que a zona rural se distingue destas últimas pelo facto de os aprendentes, na sua maior parte, preferirem comunicar-se em Português e numa língua bantu. No que diz respeito às orientações motivacionais, constata-se que a zona urbana se distingue quanto às escolhas dos aprendentes em termos das línguas que gostariam de aprender melhor, dado que a maior parte manifesta o desejo de aprender melhor uma língua bantu por razões instrumentais relacionadas com a comunicação. Pelo 
contrário, nas zonas suburbana e rural, a maior parte dos aprendentes manifesta o desejo de aprender melhor o Português por razões integrativas associadas ao prestígio desta língua e por razões instrumentais relacionadas ao acesso a emprego, à comunicação e a importância do Português para o sucesso escolar.

\section{Conclusões e perspectivas de investigação}

O presente artigo tinha como objectivo fornecer um panorama geral dos estudos sobre a aquisição do Português L2 em Moçambique. Os resultados deste trabalho revelam que a dinâmica da investigação sobre a aquisição do Português L2 tem sido particularmente dominada por estudos que procuram fornecer dados referentes à descrição linguística das gramáticas de interlíngua dos aprendentes desta língua. Tais estudos englobam temáticas que se relacionam com os estágios intermediários das gramáticas de interlíngua, com o papel da transferência linguística, com o padrão de desenvolvimento linguístico dos aprendentes do Português L2 e o papel do contexto social na aquisição do Português.

Os estudos sobre a aquisição do Português em Moçambique são ainda bastante raros, sendo a área da sintaxe aquela em que foi desenvolvida a maior parte da pesquisa realizada. Conforme se viu, à excepção do uso da preposição com, da concordância (nominal e verbal) e da flexão de verbos irregulares, em todas estas áreas, os principais tópicos gramaticais abrangidos pelos estudos dizem respeito às estruturas e conectores de subordinação e ao comportamento sintáctico de argumentos verbais com o papel de beneficiário, locativo e direccional.

Apesar de os estudos apresentados constituírem uma base útil para o conhecimento de algumas dificuldades decorrentes do facto de o Português constituir uma L2 para os aprendentes desta língua, é preciso reconhecer que existem ainda muitas lacunas de informação que precisam de ser preenchidas com base na pesquisa a ser realizada quer através do alargamento das áreas gramaticais estudadas, quer através da adopção de outras perspectivas de investigação (teóricas e metodológicas) que têm sido desenvolvidas no campo da AL2 em geral. Em primeiro lugar, existe uma necessidade de expandir o âmbito das áreas gramaticais cobertas pelos estudos apresentados nesta pesquisa quer em termos de descrição puramente gramatical, quer em termos do aprofundamento do papel das línguas bantu na sua aquisição (nos casos aplicáveis). Estão neste caso, 
por exemplo, tópicos relacionados com a aquisição da fonologia, do léxico e de determinados aspectos de sintaxe e morfo-sintaxe como a colocação dos pronomes pessoais átonos, uso dos artigos, selecção do tempo/modo verbal, flexão do infinitivo e a flexão casual dos pronomes pessoais, entre outros. Em segundo lugar, assumindo que "a estabilização da gramática do PM decorre da actuação de factores extralinguísticos relacionados com o ambiente multilingue em que ocorre a sua aquisição" (GONÇALVES, 2010, p. 199), há necessidade de desenvolver pesquisas que se ocupem da análise do papel dos factores externos relacionados com os micro e macro-contextos sociais em que a aquisição do Português L2 ocorre. Em terceiro lugar, refira-se à necessidade de desenvolver estudos sobre o efeito das diferenças individuais dos aprendentes na aquisição de L2 particularmente no que diz respeito aos factores gerais como a motivação e a aptidão linguística, incluindo as estratégias de aprendizagem que os aprendentes adoptam durante o processo de aquisição do Português L2. Finalmente, considera-se igualmente fundamental realizar pesquisas que tratem do papel da instrução formal na aquisição do Português L2 quer sob ponto de vista da forma como os usos linguísticos influenciam o decurso e o sucesso da aquisição, quer sob o ponto de vista dos efeitos da intervenção didáctica no processo de aquisição do Português L2. Esta última perspectiva de investigação permitirá traçar as linhas gerais de orientação sobre a elaboração de materiais em Português L2 com dados autênticos que sejam familiares aos aprendentes, fornecendo dados concretos para uma reflexão mais aprofundada das lacunas e deficiências dos programas de língua portuguesa em Moçambique.

\section{Referências}

ALMEIDA, Margarida. Concordância verbal: uma análise de erros do discurso de crianças da $3^{\mathrm{a}}$ classe em Moçambique. 2001. 56 f. Tese (Licenciatura em Linguística) - Universidade Eduardo Mondlane, Maputo, 2001.

CANDE, Elsa. O argumento locativo dos verbos de movimento no Português falado por crianças do terceiro ano de escolaridade. 2001. $67 \mathrm{f}$. Tese (Licenciatura em Linguística) - Universidade Eduardo Mondlane, Maputo, 2001. 
COMPANHIA, Carlito. Uso da morfologia flexional de número em sintagmas nominais plurais na interlíngua de crianças da $3^{a}$ Classe. 2001. $71 \mathrm{f}$. Tese (Licenciatura em Linguística) - Universidade Eduardo Mondlane, Maputo, 2001.

COMPANHIA, Carlito. Aquisição do Português L2 em Moçambique: papel do contexto social no desenvolvimento linguístico de alunos da $7^{a}$ Classe. 2016. $110 \mathrm{f}$. Tese (Doutoramento em Linguística) - Universidade Eduardo Mondlane, Maputo, 2016.

DIAS, Hildizina. Análise de erros da preposição com produzidos por alunos moçambicanos. In: DIAS, Hildizina. (Org.) Português Moçambicano: estudos e reflexões. Maputo: Livraria Universitária, 2009a, p. 227-253.

DIAS, Hildizina. O parâmetro do sujeito nulo em aprendentes do Português em Moçambique. In: DIAS, Hildizina (Org.) Português Moçambicano: estudos e reflexões. Maputo: Livraria Universitária, 2009b, p. 17-46.

DINIZ, Maria João. Análise de erros na frase relativa. Tese (Licenciatura em Linguística) - Universidade Eduardo Mondlane, Maputo, 1986.

DZECO, José. Estratégias didácticas adoptadas pelos professores para o ensino da concordância nominal em número nas escolas primárias moçambicanas localizadas nas zonas rurais. 2011. $105 \mathrm{f}$. Tese (Mestrado em Linguística) - Universidade Eduardo Mondlane, Maputo, 2011.

GONÇALVES, Perpétua. A Génese do Português de Moçambique. Lisboa: Imprensa Nacional-Casa da Moeda, 2010.

GONÇALVES, Perpétua; MACIEL, Carla. Estruturas de subordinação na aquisição do Português/língua segunda. In: GONÇALVES, Perpétua. (Org.) Mudanças do Português em Moçambique: aquisição e formato de estruturas de subordinação. Maputo: Livraria Universitária, 1998, p. 15-66.

GONÇALVES, Perpétua; NILSON, Carlos; NGUNGA, Armindo. O Português em Moçambique: Análise de erros em construções de subordinação. Maputo: Universidade Eduardo Mondlane (não publicado), 1986.

HYLTENSTAM, Kenneth; STROUD, Christopher. O conceito de uma língua segunda num contexto africano: implicações para a pesquisa e teoria. In: STROUD, Christopher; TUZINE, António (Orgs.) Uso das Línguas Africanas no Ensino: problemas e perspectivas. Maputo: Instituto Nacional do Desenvolvimento da Educação, 1998, p. 219-245.

PEREIRA, Elsa. Descrição e análise de erros da frase relativa produzida por estudantes falantes do Português L1. 1991. 78 f. Tese (Licenciatura em Linguística) Universidade Eduardo Mondlane, Maputo, 1991. 
STROUD, Christopher. O corpus: antecedentes, quadro teórico e aspirações práticas. In: CHRISTOPHER, Stroud; GONÇALVES, Perpétua (Orgs.) Panorama do Português Oral de Maputo Vol. I - Objectivos e Métodos. Maputo: Instituto Nacional de Desenvolvimento da Educação, 1997, p. 11-45.

Recebido em 01/09/2017

Aceito em 21/11/2017

Publicado em 12/12/2017 